which gives proportional speed control. This means that when the arm pushes the joy-stick forward it starts at a speed slightly below the bottom previously switchcontrol speed. This means that there is no tendency for the arm to be thrown into oscillation. Further movement of the arm forward progresses through to the full former speed obtained by the ordinary switches. The voltage drop by this system does not adversely affect top speed of the system.

Now we have proportional control over speed, and by pushing the joy-stick sideways the proportional characteristic also applies to the steering, so both speed and steering are now smooth.

\title{
ELECTRICAL STIMULATION OF THE BLADDER IN CLINICAL PRACTICE
}

\author{
Professor R. Ascoli \\ Servicio Urologico dell' Ospedele C.T.R. dell' I.N.A.I.L., Milan, Italy
}

THE author studied a device, to be applied in the clinical field, which might elicit contraction of the vesical muscles by electrical stimulation. After many experiments he concluded that the most suitable current is the galvanic current of 5-millisecond-rectangular impulse, 20-50-frequency every second, and a 20-80milliamperes intensity. The device for direct application to the bladder consists of an electrode-catheter, lightly curved at the end, insulated on all sides except at the point which hooks the vesical neck; the second electrode consists of an usual electrocoagulation electrode which runs inside the electrode-catheter, leaves the latter near its inner end and is in contact with the posterior wall of the bladder. The inner part of the device is in contact with the Lewis' cystometer which records the increase of the vesical pressure. Such a device is able to elicit contraction of the vesical muscular system. Technique and results are described.

\section{Discussion}

Harris, $P$., wondered why the speaker apparently had dismissed altogether this idea of implanted electrical stimulators controlled by radio-frequency transmitter unit. This was in the early stage; they had been experimenting in Edinburgh for some little time and a dog was a very good subject for experiment. He thought that these stimulators would be further sophisticated and developed in the hope that they could be used at a very early stage after spinal injury.

Ascoli, R., said he was quite aware of the possibility here and had studied the methods of the Americans but these were very traumatic surgical procedures. It was necessary to perform a laparatomy and implant on the bladder wall an instrument which was quite heavy and space-taking. On several occasions it had been necessary to re-operate because of defective instrumentation within the abdomen and most of the experiments up till now had been conducted on animals and very few on humans.

Rossier, A. (Switzerland), said he would like to ask Professor Ascoli the following. question: He had said that he had observed during stimulation contraction of abdominal muscles and muscles of the thigh, and he had suggested that this could be useful. He would like to ask whether Professor Ascoli was sure that this was useful and not damaging, because of the following fact. If one had contraction of the striated muscles of the pelvic 
floor, which also coincided with contraction of the external urethral sphincter as shown by cystography during stimulation of the bladder, this could explain the high residual urine.

Ascoli, R., replied that the electrical stimulation was not used in spastic bladdersi.e. in upper neurone lesions. It was used only in flaccid cases-i.e. cauda equina lesions or in lesions where innervation of the abdominal muscles was absent. One knew that the abdominal contraction was very important in the act of micturition, and in cases where the abdominal muscles were present the act of voiding was possible. In other cases the bladder was practically completely isolated and therefore had to be stimulated.

Benassy, $\mathcal{F}$. (France), said he had tried many times to use electronic devices for the bladder. Up to now they were always a failure, but they were continuing to try. They used them mainly in two cases: (a) Retention of the bladder in a case with hyperspasticity. The result was very bad because the spasticity was due to spasticity of the smooth muscles and after electronic stimulations, of course, it was worse. One wanted relaxation rather than stimulation. (b) In a case of low cauda equina, the incontinence was due to paralysis of the flaccid muscles of the pelvis and these flaccid muscles did not respond to electronic stimulation. In this case again they gained nothing.

\title{
A CASE OF TRANSPOSITION OF THE MUSCULO-CUTANEOUS NERVE UPON THE MEDIAN NERVE
}

\author{
By Jean Benassy, M.D. \\ Hospital Raymond-Poincare, Paris Garches, France
}

We should like to report a case of successful transposition of the musculo-cutaneous nerve upon the median nerve in a tetraplegic patient, which is of interest both in the field of paraplegia as well as of peripheral nerve surgery.

\section{Case History}

A. W., 37 years old, was involved in a motor-car accident on I 2 January I962, and sustained a tetraplegia as a result of a fracture dislocation of the 5th cervical vertebra upon the 6th.

He was admitted first to a hospital of the nearest town, and on I3 January transferred to a neurosurgical service in Paris. On I5 January 1962, it became necessary to perform a tracheostomy, which was discontinued on 22 February 1962.

The patient was transferred on 28 February 1962 to Garches, where he remained up to March I963. He did not develop any complications, such as pressure sores, periarticular ossifications or urinary infection, and the rehabilitation of the bladder was good.

Eleven months after the accident, the muscular recovery was as follows:

Right Side

Very good function (5) of what we call the 5 th cervical root distribution:

Deltoideus

Supra-spinatus

Infra-spinatus

Biceps

Brachialis

Brachio-radialis

Supinator brevis

Good function (4) in the distribution of C6: 